\title{
Análise da sensibilidade da metodologia dos centros de custos mediante a introdução de tecnologias em um sistema de produção de cria
}

\section{Ricardo Pedroso Oaigen ${ }^{1}$, Júlio Otávio Jardim Barcellos ${ }^{2}$, Luciana Fagundes Christofari ${ }^{1}$, José Braccini Neto ${ }^{3}$, Tamara Esteves de Oliveira ${ }^{4}$, Ênio Rosa Prates ${ }^{3}$}

${ }^{1}$ Curso de Pós-Graduação em Zootecnia, Faculdade de Agronomia - UFRGS.

2 Depto. de Zootecnia, Faculdade de Agronomia - UFRGS. Pesquisador CNPq.

${ }^{3}$ Depto. de Zootecnia, Faculdade de Agronomia - UFRGS.

${ }^{4}$ Curso de Graduação em Medicina Veterinária - UFRGS. Bolsista de Iniciação Científica/CNPq

RESUMO - Um modelo de simulação bioeconômico foi desenvolvido em um sistema de produção tradicional em pecuária de cria (SPT) para a aplicação da metodologia dos centros de custos com o objetivo de avaliar sua sensibilidade mediante a introdução de tecnologias de desmame precoce em vacas primíparas (SDP), campo melhorado para vacas primíparas e metade do lote das vacas secundíparas (SCM) e suplementação protéica para novilhas de reposição (SSP) destinadas a aumentar a taxa de prenhez neste sistema (SPT). As informações do desempenho biológico foram obtidas por meio de revisão bibliográfica sobre os indicadores de produção e os dados econômicos e de custos foram obtidos a partir de valores de mercado. As entradas do modelo foram: estrutura do rebanho; custos de produção; e tecnologias de produção. As saídas do modelo foram: custo operacional (CO); custo de desembolso (CD); custo de produção por centro (CPC); custo unitário por bezerro (CUB); custo por quilo desmamado (C/kg); custo anual por vaca (CAV); ponto de equilíbrio financeiro (PEF), margem operacional (MO), taxa de prenhez (TP), taxa de desmame (TD), produtividade/vaca (Pr), número de bezerros desmamados (NBD), ponto de equilíbrio em bezerros (PEB) e produção total em quilos (PT). A utilização da metodologia dos centros de custos se mostrou sensível ao identificar variações nos indicadores técnicos e econômicos e nos custos de cada centro produtivo. A introdução do SDP, SCM e SSP melhorou os indicadores técnicos e a margem operacional e, ao mesmo tempo, apresentou relação direta com as variações nos centros de custo, comprovando a sensibilidade da metodologia de custeio em relação ao impacto no SPT.

Palavras-chave: bovinos de corte, custos de produção, indicadores técnicos e econômicos, simulações

\section{Analysis of the methodology sensibility of cost centers facing the introduction of technologies in a cow-calf production system}

ABSTRACT - A bioeconomical simulation model was developed in a traditional cow-calf production system (TPS) for the application of cost center methodology with the objective of evaluating its sensibility by the introduction of early weaning technologies in primiparous cows (EWS), improved pasture for primiparous cows and half lot of secundiparous cows (IPS) and protein supplementation for replacement heifers (PSS). All technologies were used to increase the pregnancy rate in this system (TPS). Data on biological performance was obtained from a bibliographic review on production indicators and cost and economic values were obtained from market. The inputs of the model were: herd structure, production costs and production technology. The outputs of the model were: operational cost (OC); expenditure cost (EC); production costs per center (PCC); unitary cost per calf (UCC); cost per weaned kilo (WC/kg); annual cost per cow (ACC); financial break-even (FBE), operational margin (OM), pregnancy rate (PT), calf crop (CC), productivity/cow (P/C), number of weaned calves (NWC), calves break-even (CBE) and total production in kilos (TP/kg). The use of the cost center methodology was sensitive in identifying variations in the technical economic indicators and in the costs of each productive center. The introduction of EWS, IPS and PSS showed in the increase of technical indicators and in the operational margin, presented a straight relation with the changing in the cost centers, proving the sensibility of the costs methodology in relation to the impact in TPS.

Key Words: beef cattle, production costs, simulations, technical and economic indicators 


\section{Introdução}

A cria é a atividade da pecuária de corte com menor eficiência e rentabilidade. Entretanto, é a base para os demais fases de produção e toda modificação que resultar em aumento de eficiência beneficiará os demais sistemas de produção da atividade (Euclides Filho, 1997). Modificações estruturais resultariam na transformação de um setor caracterizado pela ineficiência no gerenciamento em uma empresa rural capaz de estabelecer controles, permitindo o cálculo dos indicadores zootécnicos e econômicos. Essas informações seriam úteis para a tomada de decisões, pois auxiliariam o gestor a identificar pontos de estrangulamento e traçar um planejamento para a sobrevivência da fase de cria da pecuária de corte como atividade rentável.

Entre as adversidades nessa transição, destaca-se a falta de conhecimento administrativo nos empreendimentos rurais. Portanto, torna-se um desafio desenvolver e difundir recursos de gestão capazes de suprir as necessidades da atividade, uma vez que, nas empresas familiares, essas modificações podem determinar sua permanência no setor (Short, 2001; Oaigen et al., 2006).

Uma vez financeiramente analisado o sistema produtivo, utilizam-se sistemas de análise de resultados com capacidade de abranger as inter-relações entre o biológico e o econômico do sistema de produção. Desse modo, as simulações e modelagens tornam-se úteis em centros de pesquisa, universidades e no assessoramento técnico a sistemas de produção pecuários. Pötter et al. (2000) afirmam que a análise econômica é fundamental para o produtor, pois permite a avaliação do impacto econômico de novas tecnologias no sistema. Segundo Barcellos et al. (2004), o uso do conhecimento só terá impacto sobre a eficiência e a produtividade na pecuária de cria se estiver em um contexto amplo, em uma forma de gestão integrada com todos os recursos disponíveis para a produção. Contudo, para permitir esta gestão integrada, é necessário um método padrão de custeio, associado a simulações bioeconômicas, para gerar informações e análises uniformes.

A metodologia dos centros de custos se baseia na análise do sistema de produção pecuário, a partir do mapeamento dos centros produtivos, o que permite ao empresário rural mensurar o custo de produção por meio desses centros e verificar o impacto que determinados processos e/ou tecnologias causam ao sistema, especificamente no custo final do produto (Castro et al., 2004). Segundo Figueiredo (1996), entende-se por centro de custos de uma empresa qualquer unidade de agregação de custo com uma atividade ou um conjunto de atividades com certas similaridades. No momento de apropriação dos custos de produção, deve-se diferenciar os centros diretos relacionados ao produto (bezerro no caso da pecuária de cria) e os centros indiretos não-relacionados diretamente ao produto, por exemplo, o escritório administrativo.

Neste sentido, objetivou-se verificar a sensibilidade da metodologia dos centros de custo pela introdução de tecnologias de insumos e seu impacto sobre os principais indicadores técnicos e econômicos de um sistema de cria.

\section{Material e Métodos}

As informações dos parâmetros técnicos e econômicos utilizados na simulação são provenientes de uma propriedade da Região Sul do Brasil especializada em pecuária de cria, que possui um rebanho de 750 matrizes, distribuídas em 1.500 ha de pastagens naturais, caracterizadas pela estacionalidade da produção de pasto, onde predominam espécies de crescimento estival. No inverno, os pastos naturais cessam seu crescimento a partir das primeiras geadas, ficando com baixa disponibilidade de energia e proteína.

Utilizou-se um número mínimo de fêmeas em idade de acasalamento (750), em uma área (1.500 ha) que caracteriza economia de escala, fator fundamental para a rentabilidade de sistemas de produção baseados exclusivamente em pecuária de cria.

O modelo de simulação foi baseado em uma estrutura de rebanho estática, utilizando-se planilhas interligadas do Microsoft Excel ${ }^{\circledR}$, com intervalo anual de atualização dos valores das células. As informações foram baseadas na análise de indicadores técnicos e econômicos de pecuária de cria, utilizados anteriormente em revisões bibliográficas (Barcellos, 1999; Beretta et al., 2001; Abreu et al., 2003) e na metodologia dos centros de custo (Bornia, 2002). A partir de um modelo inicial caracterizando um sistema de produção tradicional (SPT) (Figura 1) e seus indicadores técnicos (Tabela 1), foram construídas novas planilhas de análise bioeconômica, portanto, manteve-se o mesmo modelo de simulação com modificações dos coeficientes técnicos e das tecnologias utilizadas.

No sistema de produção tradicional (SPT), os bezerros são desmamados aos 7 meses de idade, com peso médio de $160 \mathrm{~kg}$ (machos) ou $140 \mathrm{~kg}$ (fêmeas), e a taxa de prenhez geral das matrizes é de $75 \%$.

Foi estipulada uma diferença de $5 \%$ entre o diagnóstico de gestação e o desmame, conseqüência de perdas embrionárias, abortos e mortalidade dos bezerros.

A distribuição das matrizes no SPT (Figura 2) permite visualizar o desempenho reprodutivo categorizado. No sistema de produção tradicional, as vacas não-prenhes 
são descartadas anualmente, após o diagnóstico de gestação, e são eliminadas do sistema de produção. Após a desmama, os bezerros são comercializados na sua totalidade e $84 \%$ das bezerras são retidas para reposição, enquanto as demais são comercializadas com os machos. A idade ao primeiro acasalamento ocorre aproximadamente aos 2 anos de idade, quando os animais apresentam aproximadamente $300 \mathrm{~kg}$ de peso corporal, e a cada ano 30\% das fêmeas são repostas.

O fluxograma entre as categorias de animais e o destino dos mesmos no decorrer do ciclo produtivo (Figura 3) possibilita o entendimento das ações e variações que ocorrem em um sistema de produção em pecuária de cria dinâmico e eficiente.

Tabela 1 - Indicadores de produtividade do sistema de produção tradicional (SPT) de cria utilizado como referência

\begin{tabular}{lcc}
\hline Parâmetro & Unidade & Valores-Períodos \\
\hline Área & hectare & 1.500 \\
Número de matrizes & cabeças & 750 \\
Taxa de prenhez & $\%$ & 75 \\
Taxa de desmame & $\%$ & 70 \\
Número de bezerros & cabeças & 525 \\
desmamados & & \\
Peso ao desmame & $\mathrm{kg}$ & 150 \\
Produção total & $\mathrm{kg}$ & 78.750 \\
Produtividade/vaca acasalada & $\mathrm{kg}$ & 105 \\
Taxa de reposição de fêmeas & $\%$ & 30 \\
Idade ao primeiro & meses & $26 / 27$ \\
acasalamento & & $1: 20$ \\
Relação touro/vaca & $\%$ & 400 \\
Peso médio da vaca adulta & $\mathrm{kg}$ & 258 \\
Carga animal - média anual & $\mathrm{kg} / \mathrm{ha}$ & Dezembro/janeiro/fevereiro \\
Época de acasalamento & - & Déril \\
Época de parição & - & Setembro/outubro/novembro \\
Mês de desmame & - & Abril \\
Mês de venda & - &
\end{tabular}

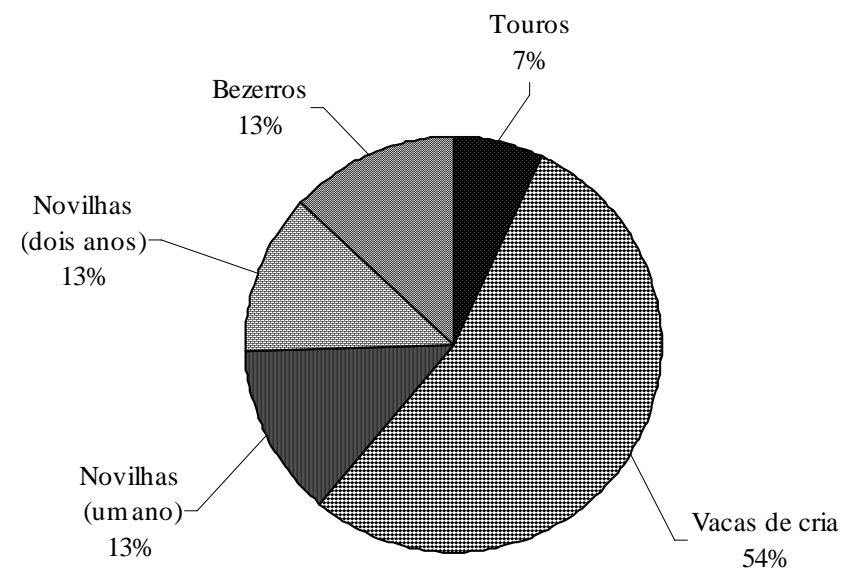

Figura 1 - Estrutura de um rebanho de cria, em unidades animais.

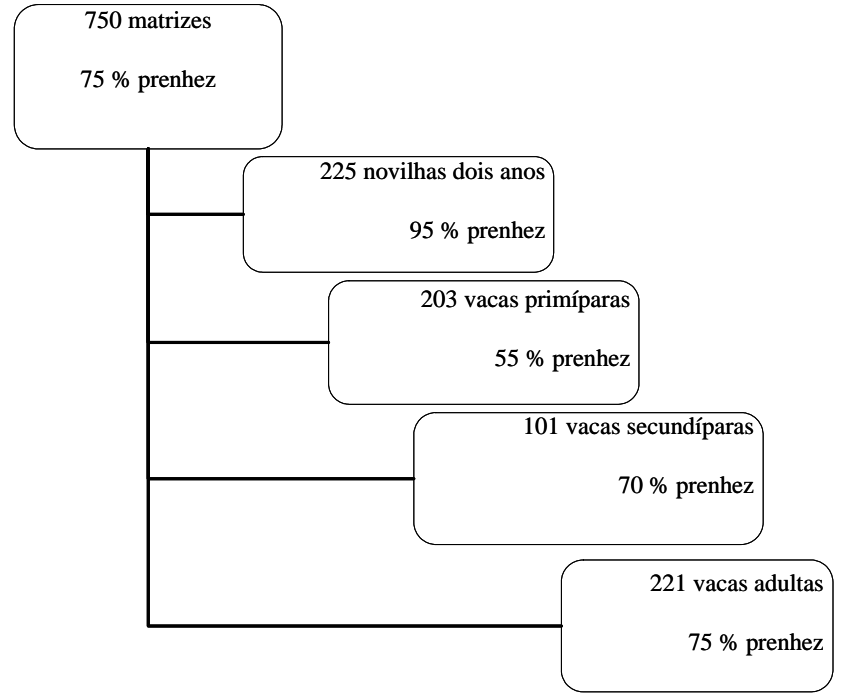

Figura 2 - Distribuição e desempenho reprodutivo das matrizes no sistema de produção tradicional.

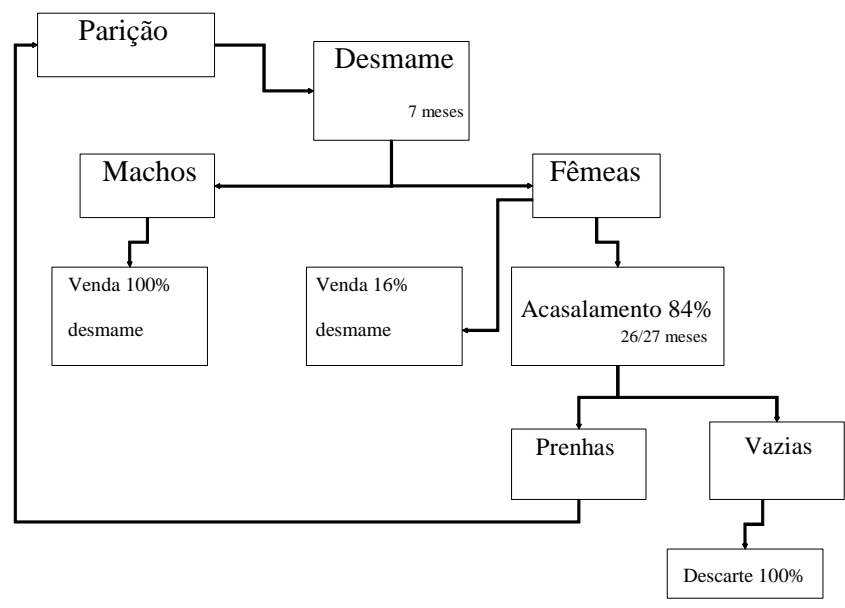

Figura 3 - Fluxograma de um sistema de produção em pecuária de cria.

Os principais centros de custos diretos utilizados no modelo de simulação foram: desmame dos bezerros, recria das novilhas, vacas de cria e os touros. Os indiretos foram bens do inventário, como máquinas, implementos, benfeitorias e veículos, e a administração da propriedade. $\mathrm{O}$ critério para o rateio dos custos comuns a vários centros (indiretos) foi realizado de acordo com Santos \& Marion (1993), a partir da composição do rebanho, constituída de unidades animais (UA = $450 \mathrm{~kg}$ ) (Figura 1). No centro de custos de recria de novilhas, foram consideradas as novilhas de 1 e de 2 anos, apropriando rateio de $26 \%$ a este centro.

Os custos de produção utilizados neste estudo foram subdivididos em fixos (impostos, seguros, mão-de-obra e depreciação) e variáveis (reprodução, sanidade, combus- 
tíveis, suplementação animal, pastagens, manutenção, arrendamentos, despesas administrativas e outros). A depreciação e os impostos foram calculados de acordo com dados regionais, todos ajustados ao módulo de 1.500 hectares. O método linear foi utilizado para o cálculo da depreciação (Santos \& Marion, 1993). Para o cálculo da mão-de-obra, foi determinado que a propriedade possui três empregados fixos, cada um com custo de salários, encargos sociais e alimentação de R \$ 700,00/mês, totalizando R\$ 25.200,00/ano. Como não constituiu objetivo avaliar a rentabilidade da atividade, a remuneração da terra e do capital não foi considerada. Todos os dados para cálculo dos custos de produção foram obtidos a partir de preços praticados no mercado em dezembro de 2006, visando aferir a eficiência e a sensibilidade do método.

Foram avaliadas três tecnologias introduzidas no sistema de produção tradicional, destinadas exclusivamente a aumentar a taxa de prenhez;

- desmama precoce em vacas primíparas (SDP): foram considerados neste processo os custos do concentrado fornecido aos bezerros, com $18 \%$ de proteína bruta (PB), na base de 1 a 1,5 kg/cabeça/dia, da sanidade (vacinas e vermífugos) e da mão-de-obra, todos apropriados ao centro de custo desmame dos bezerros. Considerou-se, pela introdução dessa tecnologia, aumento de $30 \%$ na taxa de prenhez das 203 vacas primíparas, de 55\% para 85\% (Gottschal, 2004).

- campo melhorado para vacas primíparas e secundíparas no pós-parto (SCM): foram considerados neste processo $20 \%$ dos custos da implantação de pastagem de azevém (Lolium multiflorum), com vida útil de cinco anos, sobressemeado em campo nativo, referente aos gastos com sementes, fertilizantes, combustível e mão-de-obra, além dos custos de manutenção anual das pastagens, apropriados ao centro de custo das vacas de cria. O benefício da introdução desta tecnologia foi medido pelo aumento de $30 \%$ na taxa de prenhez das 203 vacas primíparas (55 para $85 \%)$ e $10 \%$ na taxa de prenhez para as 51 vacas secundíparas (70 para $80 \%$ ), que representavam metade do lote desta categoria, e que estavam com baixa condição corporal na época de parição. O restante das vacas secundíparas igualmente apresentou taxa de prenhez de 80\% (Restle et al., 2000; Lopes et al., 2008).

- suplementação protéica hibernal, após o desmame, para novilhas de reposição (SSP): foram considerados neste processo os custos do concentrado, com 13\% de proteína bruta (PB) e $65 \%$ de nutrientes digestíveis totais (NDT), fornecido em quantidade correspondente a $1 \%$ do peso vivo e, da mão-de-obra, apropriados ao centro de custo recria das novilhas. Nessa simulação, foi considerada prenhez de $80 \%$ das novilhas do sistema de produção de cria, em decorrência do baixo peso ao acasalamento de $280 \mathrm{~kg}$. Nos demais sistemas, essa categoria era acasalada com $300 \mathrm{~kg}$ e tinha taxa de prenhez de 95\%. Portanto, o objetivo com a tecnologia foi aumentar o peso ao primeiro acasalamento para melhorar a taxa de prenhez em 10\% (80 para 90\%) nas 225 novilhas (100\% lote). A taxa de prenhez das vacas adultas aumentou de $75 \%$ para $85 \%$, como conseqüência da diminuição da carga animal destinada para a categoria, pela liberação de uma área anteriormente destinada às novilhas de reposição e que passaram a receber suplementação (Lobato, 1999; Barcellos, 1999; Barcellos et al., 2006).

O impacto da introdução destas três tecnologias de produção foi medido por meio de um modelo bioeconômico (Figura 4), que possibilitou analisar as variações dos indicadores econômicos:

Custo operacional $=$ custos fixos $($ com depreciação $)+$ custos variáveis.

Custo de desembolso = custos fixos (sem depreciação) + custos variáveis.

Custo de produção por centro = soma total dos custos diretos e indiretos.

Custo unitário por bezerro = custo operacional total/ número de bezerros desmamados.

Custo por quilo desmamado = custo operacional total/ total de quilos de desmamados.

Custo anual por vaca $=$ custo operacional total total de fêmeas acasaladas.

Ponto de equilíbrio financeiro $=$ ponto de equilíbrio (quantidades) * preço unitário do bezerro.

Margem operacional $=$ (número de bezerros desmamados * preço unitário do bezerro) - custo operacional.

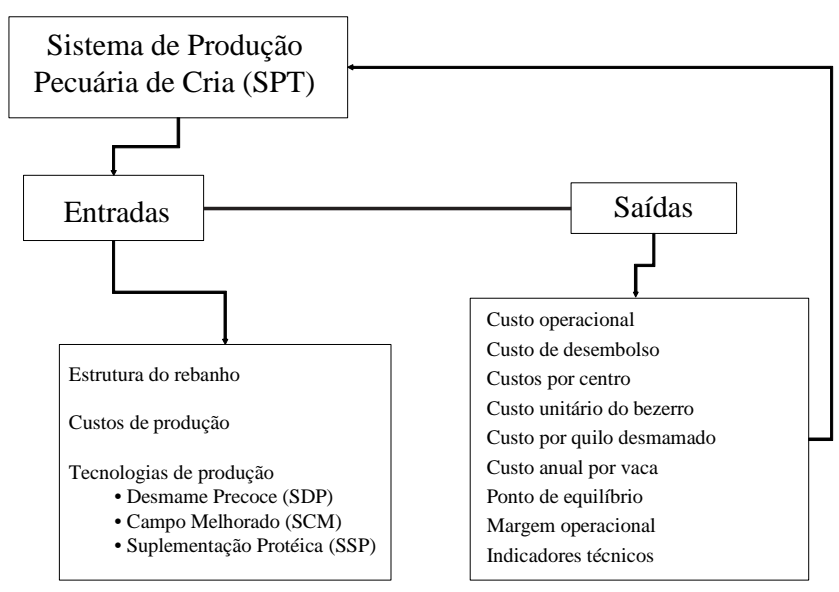

Figura 4 - Modelo de simulação do impacto de tecnologias na pecuária de cria. 
Os indicadores biológicos analisados foram:

Taxa de prenhez = número de fêmeas prenhes/número de fêmeas acasaladas

Taxa de desmame = número de bezerros desmamados/ número de fêmeas acasaladas

Produtividade/vaca = total de quilos desmamados/ número de fêmeas acasaladas

Número de bezerros desmamados $=$ total de bezerros desmamados

Ponto de equilíbrio em bezerros = custo fixo/(preço unitário do bezerro - custo variável unitário)

Produção total em quilos = total de bezerros desmamados * peso médio.

\section{Resultados e Discussão}

A estrutura de rebanho utilizada neste modelo foi calculada a partir dos indicadores técnicos (Tabela 1), mantendo-se estática em todas as simulações. A única exceção foi o número de bezerros desmamados (Tabela 2), que foi alterado de acordo com a taxa de prenhez obtida, pela introdução da tecnologia, fazendo com que os valores de alguns indicadores sofressem pequena variação. Para esta análise, foi considerado um período de 12 meses, que representa um ciclo produtivo do bezerro.

Nas análises da variação nos indicadores econômicos (Tabela 3), constaram somente as vendas de bezerros e

Tabela 2 - Indicadores técnicos dos sistemas de produção avaliados

\begin{tabular}{lcccc}
\hline Indicador técnico & \multicolumn{4}{c}{ Sistema de produção } \\
\cline { 2 - 5 } & Tradicional & Desmame precoce & Campo melhorado & Suplementação protéica \\
\hline Taxa de prenhez (\%) & 75 & 83 & 84 & 77 \\
Taxa de desmame (\%) & 70 & 78 & 79 & 72 \\
Bezerros desmamados (cabeça) & 525 & 585 & 595 & 539 \\
Ponto de equilíbrio (cabeça) & 258 & 224 & 250 & 263 \\
Produção total (kg) & 78.750 & 87.750 & 119 & 80.809 \\
Produtividade/vaca (kg) & 105 & 117 & 108 \\
\hline
\end{tabular}

Tabela 3 - Custos de produção e indicadores econômicos dos sistemas de produção

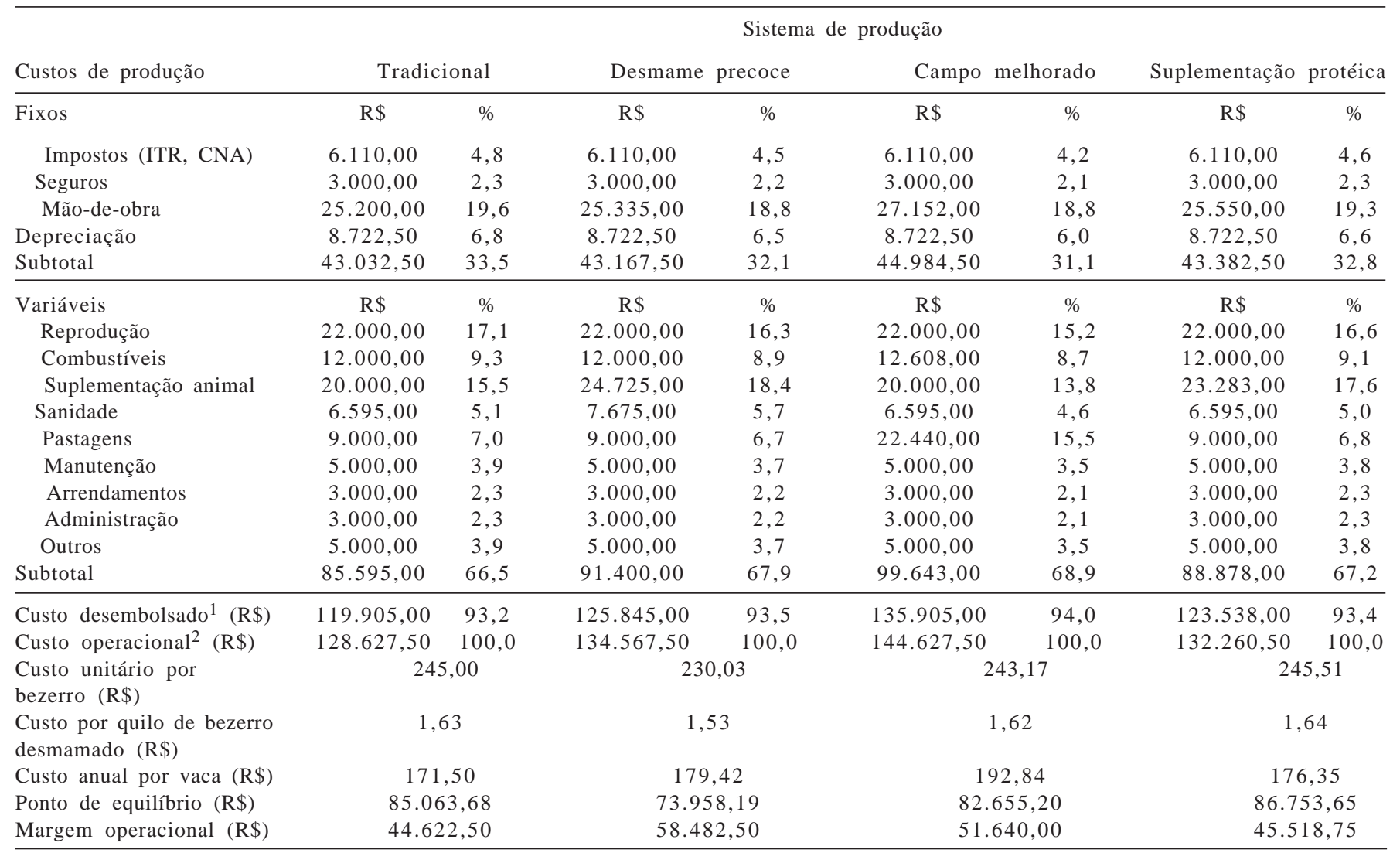

Custo desembolsado $=$ custos fixos $($ sem depreciação $)+$ custos variáveis.

Custo operacional $=$ custos fixos (com depreciação) + custos variáveis. 
foram excluídos os valores das vacas de descarte. O ponto de equilíbrio financeiro e o ponto de equilíbrio em bezerros da simulação foram calculados a partir dos valores do custo fixo, do custo variável unitário (custo variável/número de bezerros desmamados) e do preço de mercado, considerando o valor de R \$330,00/bezerro em todas as simulações, independentemente da época de comercialização. Não foram considerados os valores de remuneração da terra e do capital, o que aumentaria consideravelmente o ponto de equilíbrio.

A tecnologia de desmama precoce em vacas primíparas apresentou valores inferiores para o ponto de equilíbrio financeiro e o ponto de equilíbrio em bezerros. Ao mesmo tempo, a margem operacional foi superior à dos outros sistemas, mesmo com menor número de bezerros em comparação ao sistema de campo melhorado, conseqüência do aumento da produtividade associado ao custo variável unitário reduzido. Igualmente, o custo de produção por bezerro e o custo por quilo desmamado foram menores no sistema de desmame precoce em comparação aos sistemas de produção de cria, de campo melhorado e de suplementação protéica, comprovando que a redução dos custos é diretamente relacionada à rentabilidade quando a produtividade da empresa rural aumenta, como resultado dessa introdução de tecnologia. Ramsey at al. (2005) determinaram fatores interdependentes que afetam o desempenho econômico de rebanhos de cria, entre eles, os custos de produção, a produtividade biológica e a lucratividade do sistema.

Atualmente, o avanço tecnológico tem possibilitado aumentar a eficiência produtiva, sobretudo pelo aumento da produtividade por área e por animal, diluindo custos fixos por bezerro desmamado. Entretanto, a lucratividade da pecuária de cria apresenta grande variabilidade, em decorrência das características intrínsecas e complexas da atividade e de cada sistema de produção, o que torna importante a quantificação dessas relações. McGrann et al. (1993), por meio da análise do desempenho bioeconômico de rebanhos de cria, demonstraram existir correlações positivas do percentual de prenhez e da taxa de desmame com a rentabilidade e correlações negativas do custo anual de vacas com a rentabilidade dos sistemas de produção. De acordo com Beretta et al. (2001), a taxa de natalidade de um rebanho de cria é a variável que causa maior impacto sobre a rentabilidade de um sistema de produção, principalmente com o aumento de $50 \%$ para $70 \%$, o que melhora a margem econômica da atividade, pela maior taxa de descarte de vacas e desfrute. Abreu et al. (2003) ressaltaram o impacto econômico no sistema com o aumento da taxa de natalidade de $65 \%$ para $70 \%$, que eleva em média $16,3 \%$ o número de animais vendidos. Nesta simulação, o aumento foi de 8, 9 e $2 \%$ na taxa de prenhez e de 31,$1 ; 15,7$ e 2,0\% na margem operacional, respectivamente, nos sistemas de produção desmame precoce, campo melhorado e suplementação protéica em comparação ao sistema de produção tradicional, o que comprova que, independentemente da tecnologia introduzida, houve variações positivas no desempenho econômico.

Esses resultados denotam a importância da avaliação da viabilidade de implantação de uma nova tecnologia considerando o funcionamento global do sistema de produção e não apenas das categorias afetadas. Segundo Beretta et al. (2001), em termos gerais, a resposta à incorporação de tecnologia ao processo produtivo é positiva e aumenta de foram decrescente conforme o sistema se torna mais intensivo. Esse tipo de comportamento torna a empresa muito sensível às mudanças nos preços dos insumos.

Abreu et al. (2006) avaliaram a eficiência da introdução de tecnologias em um sistema extensivo de cria por meio da análise envoltória de dados (DEA), cujo objetivo por meio da programação linear é mensurar o desempenho relativo de unidades organizacionais com múltiplos insumos e produtos relativamente homogêneos. De forma geral, as propriedades rurais possuem grande número de entradas e saídas, complexidade que pode ser incorporada na mensuração da eficiência, pela razão da soma ponderada dos produtos pela soma ponderada dos insumos.

A partir da distribuição dos custos aos respectivos centros de custos (Figura 5), são calculados os núcleos produtivos responsáveis pelas movimentações financeiras na empresa rural, o que possibilita aos administradores tomar decisões de acordo com o desempenho medido, ou seja, centros de custos com elevados desembolsos e baixa produtividade são analisados detalhadamente buscando identificar as causas dessa situação. Peres et al. (2004) utilizaram a simulação de Monte Carlo para analisar o valor presente líquido e a taxa interna de retorno de três sistemas de recria de novilhas e afirmaram que conhecer as variáveis com maior peso na determinação dos resultados de cada sistema é de extrema importância, pois, ao identificar os itens de maior impacto econômico, é possível evitar erros nas decisões.

Neste trabalho, houve variação entre os centros em relação aos sistemas, o que comprova sensibilidade desta metodologia de custeio às alterações no modelo de simulação proposto. Segundo Jorge Jr. et al. (2006), para um modelo ser considerado válido, as decisões obtidas devem ser similares àquelas que seriam tomadas em um modelo físico de mesma natureza, tornando possível adaptá-lo para outras circunstâncias de produção, mediante mudanças nos indicadores técnicos e econômicos utilizados, assim como nos custos de produção. Caso não seja considerado 


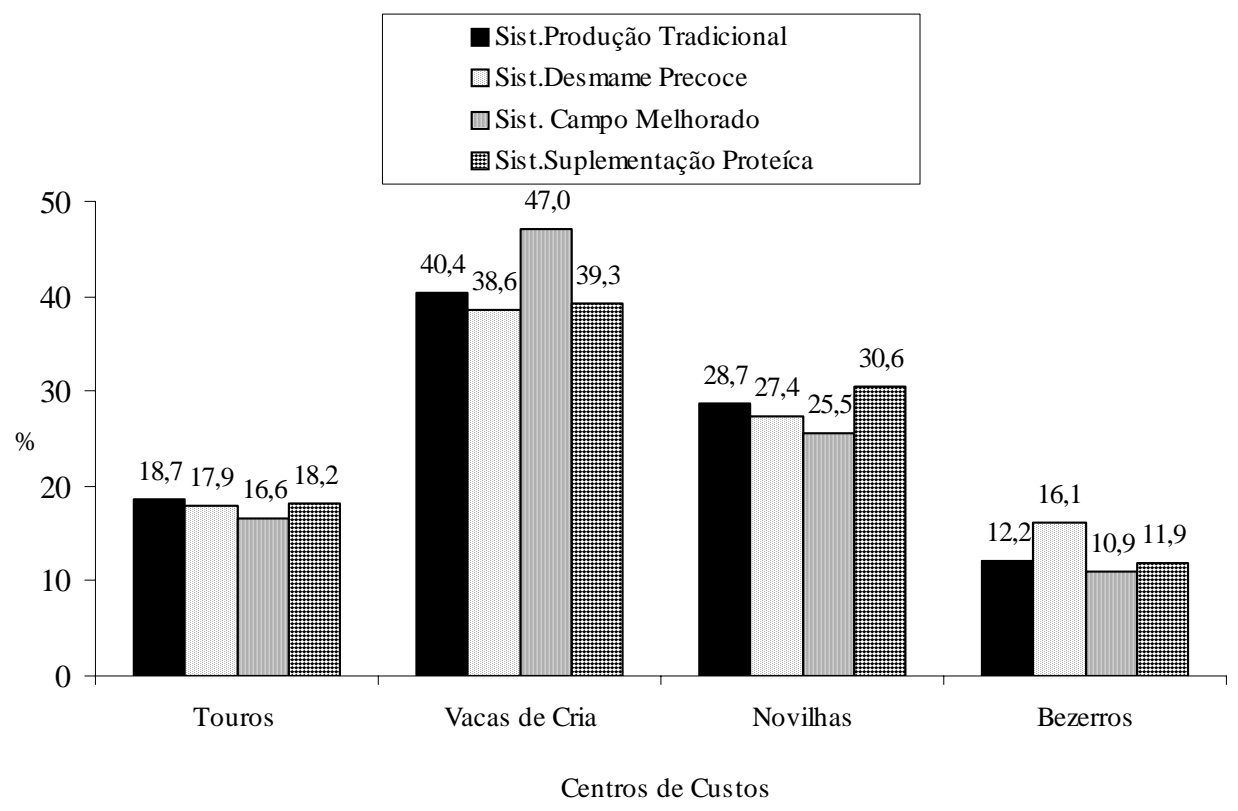

Figura 5 - Percentual de custos por centro produtivo em cada sistema de produção.

válido, quaisquer conclusões derivadas a partir de um modelo são consideradas duvidosas.

O centro das vacas de cria (centro direto) engloba a maior parcela dos custos neste sistema de produção, independentemente da tecnologia introduzida, conseqüência da maior apropriação a esta categoria dos custos indiretos (rateios), em virtude do maior número de unidades animais, 54,2\% (Figura 1).

Alterações na distribuição dos custos aos centros ocorrem quando se incluem, por exemplo, os custos do desmame precoce no centro de custo bezerros e da suplementação protéica no centro novilhas, o que aumenta a participação de 12,2 para $16,1 \%$ e de 28,7 para 30,6\%, respectivamente. No centro das vacas de cria, a variação mais importante ocorre a partir do melhoramento do campo nativo pela introdução de azevém (SCM), ocasionando aumento de 40,4 para 47,0\% na participação deste centro em relação aos custos totais. Em contrapartida, a margem bruta apresenta aumento positivo de $15,7 \%$, como resultado da melhora na taxa de desmame e na produtividade/ vaca do sistema de campo melhorado.

Segundo Oaigen et al. (2008), conhecer o custo de produção por meio de centros geradores de custos permite ao empresário rural compreender o impacto que determinados processos e/ou tecnologias causam ao sistema, especificamente no custo final do produto. Neste sentido, determinar o custo do bezerro de corte, bem como sua composição, são ferramentas essenciais para uma pecuária de corte rentável e eficiente e diminuem os riscos e as incertezas em um mercado competitivo.
O custo operacional aumentou com a introdução de tecnologias, indicando que, em sistemas intensivos, ocorrem aumentos significativos dos custos variáveis, sobretudo do item alimentação animal. Neste trabalho, o aumento do custo operacional foi de 2,9 e 2,1\% para a suplementação animal e de $8,5 \%$ nas pastagens, respectivamente, nos sistemas de produção desmame precoce, suplementação protéica e campo melhorado, em comparação ao sistema de produção tradicional. De acordo com Falconer et al. (1999), os custos de alimentação e pastagens são os principais componentes do custo total de produção na cria. Segundo Paterson (2003), esses custos representam 60\% do desembolso anual, $35 \%$ relativo às pastagens e $25 \%$ aos suplementos alimentares. Desse modo, os gestores devem avaliar quais técnicas disponíveis apresentam custo/benefício favorável para que possam ser adotadas.

\section{Conclusões}

A utilização da metodologia dos centros de custos em sistemas de cria permite detectar variações nos custos diretos e nos indicadores econômicos e biológicos. A introdução de tecnologias de produção possibilita atingir margens operacionais superiores em relação ao sistema de produção tradicional. A utilização desse modelo de avaliação de custos em empresas rurais possibilita comparações entre os resultados obtidos e permite estimar os benefícios da introdução de novas tecnologias, por meio dos indicadores técnicos e econômicos, além de fornecer informações que podem auxiliar nas decisões. 


\section{Literatura Citada}

ABREU, U.G.P.; CEZAR, I.M.; TORRES, R.A. Análise bioeconômica da introdução de período de monta em sistemas de produção de rebanhos de cria na região do Brasil Central. Revista Brasileira de Zootecnia, v.30, n.5, p.1198-1206, 2003.

ABREU, U.G.P.; LOPES, P.S.; BAPTISTA, A.J.M.S. et al. Avaliação da introdução de tecnologias no sistema de produção de gado de corte no Pantanal: análise de eficiência. Revista Brasileira de Zootecnia, v.35, n.3, p.1242-1250, 2006.

BARCELlOS, J.O.J.; DALMANN, M.D.; PRATES, E.R. et al. Taxas de prenhez em novilhas de corte acasaladas aos 18 e 24 meses. Arquivo Brasileiro de Medicina Veterinária e Zootecnia, v.58, n.6, p.1168-1173, 2006.

BARCELLOS, J.O.J. Manejo integrado: um conceito para aumentar a produtividade dos sistemas de produção de bovinos de corte. In: LOBATO, J.F.P.; BARCELLOS, J.O.; KESSLER, A.M. (Eds.). Produção de bovinos de corte. Porto Alegre: EDIPUC, 1999. p.287-313.

BARCELLOS, J.O.J.; SUNE, Y.B.P.; SEMMELMANN, C.E.N. et al. A bovinocultura de corte frente a agriculturização no sul do Brasil. In: CICLO DE ATUALIZACAO EM MEDICINA VETERINARIA, 11., 2004, Lages. Anais... Lages: CAMEVUDESC, 2004. p.13-30.

BERETTA, V.; LOBATO, J.F.P.; MIELITZ NETO, C.G.A. Produtividade e eficiência biológica de sistemas pecuários de cria diferindo na idade das novilhas ao primeiro parto e na taxa de natalidade do rebanho no Rio Grande do Sul. Revista Brasileira de Zootecnia, v.30, n.4, p.1278-1286, 2001.

BORNIA, A.C. Análise gerencial de custos: aplicação em empresas modernas. Porto Alegre: Bookman, 2002. 203p.

CASTRO, A.G.; PEREIRA, M.L.; KLIEMANN NETO, F.J. Desenvolvimento de um sistema de custos para uma empresa do ramo metal-mecânico. In: ENCONTRO NACIONAL DE ENGENHARIA DE PRODUÇÃO, 24., 2004, Florianópolis. Anais... Florianópolis: ABEPRO, [2004]. (CD-ROM).

EUCLIDES FILHO, K. A pecuária de corte no Brasil: novos horizontes, novos desafios. Campo Grande: EMBRAPA-CNPGC, 1997. 28p. (Documentos, 69).

FALCONER, L.L.; PARKER, J.L.; McGRANN, J.M. Cost of production analysis for the Texas cow-calf industry. Texas Journal of Agriculture and Natural Resources, v.12, p.7-13, 1999.

FIGUEIREDO, R.S. Sistemas de apuração de custos. In: BATALHA, M.O. (Ed.). Gestão agroindustrial. São Paulo: Atlas, 1996, p.381-464.

GOTTSCHALL, C.S. Desmame de terneiros: ferramenta para aumento da eficiência em rebanhos de corte. A Hora Veterinária, v.142, p.9-12, 2004.
JORGE JR., J.; CARDOSO, V.L.; ALBUQUERQUE, L.G. Modelo bioeconômico para calculo de custos e receitas em sistemas de produção de gado de corte visando a obtenção de valores econômicos de características produtivas e reprodutivas. Revista Brasileira de Zootecnia, v.35, n.5, p.2187-2196, 2006.

LOBATO, J.F.P. Considerações efetivas sobre seleção, produção e manejo para maior produtividade dos rebanhos de cria. In: LOBATO, J.F.P.; BARCELLOS, J.O.; KESSLER, A.M. (Eds.). Produção de bovinos de corte. Porto Alegre: EDIPUC, 1999. p.235-285

LOPES, M.L.T.; CARVALHOS, P.C.F.; ANGHINONI, I. et al. Sistema de integração lavoura-pecuária: desempenho e qualidade da carcaça de novilhos superprecoces terminados em pastagem de aveia e azevém manejada sob diferentes alturas. Ciência Rural, v.38, p.178-184, 2008.

McGRANN, J.M.; PARKER, J.L.; FALCONER, L.L. et al. Standardized Performance Analysis (SPA) - IRM-SPA Hand-Book Articles. Texas: Department of Agricultural Economics, 1993. 342p.

OAIGEN, R.P.; BARCELLOS, J.O.J.; CHRISTOFARI, L.F. et al. Melhoria organizacional na produção de bezerros de corte a partir dos centros de custos. Revista Brasileira de Zootecnia, v.37, n.7, p.580-587, 2008.

OAIGEN, R.P.; BARCELLOS, J. O. J.; CHRISTOFARI, L.F. et al. Custos de produção em bezerros de corte: uma revisão. Veterinária em Foco, v.3, n.2, p.169-180, 2006.

PATERSON, J. [2003]. Beef cow management: keeping up with the change. Disponível em: <http://www.animal rangeextension.montana.edu/articles/beef/ market/change.pdf.> Acesso em: 30/12/2006.

PERES, A.A.C.; SOUZA, P.M.; MALDONADO, H. et al. Análise econômica de sistemas de produção a pasto para bovinos no município de Campos de Goytacazes-RJ. Revista Brasileira de Zootecnia, v.33, n.6, p.1557-1563, 2004.

PÖTTER, L.; LOBATO, J.F.P.; MIELITZ NETO, C.G.A. Análise econômica de modelos de produção com novilhas de corte, primíparas aos dois, três e quatro anos de idade. Revista Brasileira de Zootecnia, v.29, n.3, p.861-870, 2000.

RAMSEY, R.; DOYE, D.; WARD, C. et al. [2005]. Factors affecting beef cow-herd costs, production, and profits. Disponível em: <http:// findarticles. com/p/ articles/mi_qa4051/is_200504/ ai_n13635246> Acesso em: 3/9/2006.

RESTLE, J.; ROSO, C.; SOARES, A.B. et al. Produtividade animal e retorno econômico em pastagem de aveia preta mais azevém com fontes de nitrogênio em cobertura. Revista Brasileira de Zootecnia, v.29, n.2, p.357-364, 2000.

SANTOS, G.J.; MARION, J.C. Administração de custos na Agropecuária. São Paulo: Atlas, 1993. 141p.

SHORT, S.D. [2001]. Characteristics and production cost of U.S cow-calf operations. Disponível em: <http:// www.ers.usda.gov> Acesso em: 2/9/2006. 